\title{
Why Do Patients Miss Dental Appointments in Eastern Province Military Hospitals, Kingdom of Saudi Arabia?
}

\author{
Ambreen Shabbir ${ }^{1}$, Mohammad Alzahrani ${ }^{2}$, Areej Abu Khalid ${ }^{3}$ \\ 1. Pathology, Prince Sultan Military College of Health Sciences, Dhahran, Kingdom of Saudi Arabia 2. Vice Dean for \\ Development and Quality, Department of Dental and Oral Health, Prince Sultan Military College of Health Sciences, \\ Dhahran, Kingdom of Saudi Arabia 3. Chairperson, Department of Dental and Oral Health, Prince Sultan Military \\ College of Health Sciences, Dhahran, Kingdom of Saudi Arabia
}

Corresponding author: Ambreen Shabbir, drambreen2018@gmail.com

\begin{abstract}
No-shows for scheduled appointments are a frequent occurrence, creating unused appointment slots and reducing patient quality of care and access to services while increasing loss to follow-up and medical costs. The aim of our study was to determine the factors that lead to patients missing their dental appointments in Eastern Province Military Hospitals, Kingdom of Saudi Arabia. The study population included military personnel and their families attending the dental clinics of these hospitals. In our study, the percentage of missed appointments was $58.1 \%$, while $54.4 \%$ of participants canceled dental appointments in the past. Thirty-six percent preferred morning appointments while $56 \%$ preferred an afternoon appointment and were likely to miss a morning appointment if given one. The most common reasons for missing an appointment were forgetting about it (24.3\%) and the inability to get time off either from work or school (15.4\%); $1.5 \%$ of patients stated they had a bad dental experience and feared dental treatment while the unavailability of transport accounted for $0.7 \%$ of patients. Of the reasons given for canceling an appointment, the inability to get time off from work/school was the most common (22.1\%) while a dislike for treatment was the least common (0.7\%). Canceling an appointment was significantly correlated with missing an appointment among the surveyed sample $(\mathrm{P}=0.00)$. In our research, $60.3 \%$ of participants still relied on their personal diary to remember appointments, which could be a reason for the high rate of missed appointments. Fifty-nine percent of respondents felt that missing an appointment was important to them, while $72 \%$ stated that missed appointments could affect the work of the clinic but still believed that automatic appointments should be given to patients who missed them and a change be made accordingly. Since major factors included a lack of a reminder message and appointments scheduled at inconvenient timings, some steps that can help reduce the frequency of missed appointments include sending a reminder message to patients, giving preference to their schedules for appointments, giving patients shorter appointments, reducing intervals between subsequent appointments, and educating patients regarding the treatment plan, to reduce anxiety.
\end{abstract}

Received 02/09/2018

Review began 03/09/2018 Review ended 03/14/2018 Published 03/21/2018

๑) Copyright 2018 Shabbir et al. This is an open access article distributed under the terms of the Creative Commons Attribution License CC-BY 3.0., which permits unrestricted use, distribution, and reproduction in any medium, provided the original author and source are credited.
Categories: Other, Epidemiology/Public Health

Keywords: missed dental appointments, eastern province military hospital, kingdom of saudi arabia

\section{Introduction}

Although general medicine and surgery suffer from non-attendance, it is especially prevalent in dental practice [1], causing detrimental effects on its outcome and revenue [2-3]. Patients may miss their dental appointments for several reasons. Even if the reason is justifiable from the patient's point of view, it still has a negative impact on the clinic, which eventually trickles down to the entire health system. The impact of missed dental appointments is not as simple as it appears, as the patient not only denies dental care to himself but others as well [4]. At the same time, they interrupt their continuity of care, affect workflow, waste resources, and reduce population-wide access to care [1,5-6].

The economic effect alone of dental patients missing their appointments was estimated at around 65 pounds per appointment according to a study conducted in the United Kingdom in 1997. The same study stated that out of 14-million patients seen in outpatient dental clinics per year, the national rate of nonattendance at appointments was around $12 \%$, which cost the health ministry around 300 million pounds per year [7]. The resources employed by the dental clinic remain idle and underutilized while the dentist waits for the patient to show up and the next patient in line has to wait longer [3]. From the patient's perspective, if the diagnosis of a particular problem is delayed due to a missed appointment, it delays treatment, thus threatening the patient's dental health [6].

Most investigations related to causal factors for missing dental appointments have had low response rates (30\% to 40\%) and are difficult to interpret [7]. However, some common reasons that previous studies have unearthed include unforeseen circumstances, fear of dental treatment, lack of travel facilities, laziness, and 
forgetfulness [4]. The average non-attendance rate at outpatient clinics in the United Kingdom was reported to be $12 \%$, out of which $30 \%$ claimed forgetfulness and $8 \%$ no longer felt the need for treatment. One participant revealed that he failed to attend his appointment due to a fear of being seen by a junior doctor, who he believed was inexperienced, while another participant pointed out that he was previously mistreated by the management at the clinic [7]. Similar research conducted at the Kuwait University Dental Center suggested that most no-show dental appointments were significantly influenced by the complexity of the treatment planned, concluding that fear plays an important role in this regard, as most patients were afraid of complex procedures (root canals and extractions), the frequency of which is relatively low compared to regular check-ups [8].

Many patients in Saudi Arabia miss dental appointments each year, which has a significant impact on its health care system as well as the individual clinics [6]. No-shows not only reduce access to care but also interrupt the continuity of care and effective disease management for patients [1]. Studies conducted previously in Saudi Arabia focused more on the consequences of missed dental appointments and concentrated on college students and demographics such as gender. However, to devise a solution to this problem, it must be understood from a broader perspective in Saudi Arabia [6]. This research aimed at finding out the factors responsible for patients missing their dental appointments so preventive steps could be taken in order to reduce its devastating consequences in Eastern Province Military Hospitals, Kingdom of Saudi Arabia.

\section{Materials And Methods}

The study was conducted after receiving approval from the Research Ethics Committee, Prince Sultan Military College of Health Sciences, in Dhahran. Our target population was military officers and their families who came for their dental checkups and treatment at Armed Forces Hospital in Jubail, King Fahd Military Medical Complex in Dhahran, and Air Base Hospital in Dhahran. A total of 150 patients visiting the dental clinics were selected at random. The method for collecting data was through a self-administered questionnaire (Appendix A), which was used by researchers at King Saud University in Riyadh [9] after obtaining permission from them and was developed according to the questions mentioned in the article. For those patients who preferred answering in Arabic, the questionnaire was translated into Arabic as well. The questionnaires were handed out to patients at different times of the day and were collected once filled out. Options in the questionnaire had several category choices of "yes/no/do not know." A tickbox layout was used to provide appropriate answers. After collecting the questionnaires from the patients, the answers were coded and entered into an Excel sheet and submitted to a statistician for analysis. The distributions of all qualitative variables (i.e., closed-ended)/values of the sample were examined with frequency tables. Comparison tables were calculated to find an association wherever necessary, and for comparing variables, we used the chi-square test and McNemar's test.

\section{Inclusion criteria}

Literate patients (male/female) who are attending military hospitals in the Eastern Province were included in this study.

\section{Exclusion criteria}

Dental staff and patients who could not read or write were excluded from the study.

\section{Results}

A total of 150 questionnaires were distributed, of which 136 were received, giving us a response rate of 90.6\%. Thirty-six percent of participants were males, $64 \%$ were females, $35.3 \%$ were students, and $46.3 \%$ were employed, as depicted in Table 1. 


\section{Cureus}

Demographic variable

\begin{tabular}{|c|c|c|}
\hline Gender & Frequency & $\%$ \\
\hline Male & 49 & 36 \\
\hline Female & 87 & 64 \\
\hline Occupation & Frequency & $\%$ \\
\hline Student & 48 & 35.3 \\
\hline Employed & 63 & 46.3 \\
\hline Age Group & Frequency & $\%$ \\
\hline $12-15$ years & 5 & 3.6 \\
\hline $16-19$ years & 22 & 16 \\
\hline >20 years & 110 & 80 \\
\hline
\end{tabular}

TABLE 1: Distribution of the sample by age, gender, and occupation

We found that $60.3 \%$ respondents used their diaries and $5.9 \%$ relied on their memory for remembering their dental appointments, as seen in Table 2.

\begin{tabular}{|l|l|l}
\hline Method of Remembering Dental Appointment Date & Frequency & $\%$ \\
\hline Diary & 82 & 60.3 \\
Calendar & 14 & 10.3 \\
Memory & 8 & 5.9 \\
Another person & 4 & 2.9 \\
Mobile & 2 & 1.5
\end{tabular}

TABLE 2: Distribution of the sample by methods used for remembering appointments

When asked for the reasons why they previously canceled their dental appointments, $22.1 \%$ patients answered that they were unable to get time off from work/school and $24.3 \%$ admitted to forgetting their appointment, as tabulated in Table 3. 


\section{Cureus}

\begin{tabular}{|c|c|c|}
\hline Reason for Cancelation of the appointment & Number & $\%$ \\
\hline Inconvenient timing & 8 & 5.9 \\
\hline Unable to get off work/school & 30 & 22.1 \\
\hline Unable to get transport & 12 & 8.8 \\
\hline Sickness & 2 & 1.5 \\
\hline Fear of treatment & 2 & 1.5 \\
\hline Dislike of treatment & 1 & 0.7 \\
\hline \multicolumn{3}{|l|}{ Reason for missing the appointment } \\
\hline Forgetfulness & 33 & 24.3 \\
\hline Unable to get time off work & 21 & 15.4 \\
\hline School & 7 & 5.1 \\
\hline Unable to get transport & 1 & 0.7 \\
\hline Sickness & 2 & 1.5 \\
\hline Fear of treatment & 2 & 1.5 \\
\hline
\end{tabular}

TABLE 3: Patients' reasons for canceling and missing dental appointments

The association between missed and cancelled appointments is shown in Table 4, with chi-square $=14.10(\mathrm{p}$ $=0.00$ ). The associations between cancelled appointments and gender, missed appointments and gender, and missed appointments and age group were calculated but did not give a significant $\mathrm{p}$-value (chi-square $=$ $0.22, \mathrm{p}=0.64 ;$ chi-square $=1.57, \mathrm{p}=0.21 ;$ chi-square $=1.79, \mathrm{p}=0.41$, respectively) .

\begin{tabular}{|c|c|c|c|c|}
\hline & & \multicolumn{3}{|c|}{ Have you ever missed an appointment at this clinic? } \\
\hline & & Yes & No & Total \\
\hline \multirow{6}{*}{ Have you ever canceled an appointment at this clinic? } & \multirow{2}{*}{ Yes } & 54 & 20 & 74 \\
\hline & & $73.0 \%$ & $27.0 \%$ & $100.0 \%$ \\
\hline & \multirow{2}{*}{ No } & 25 & 36 & 61 \\
\hline & & $41.0 \%$ & $59.0 \%$ & $100.0 \%$ \\
\hline & \multirow{2}{*}{ Total } & 79 & 56 & 135 \\
\hline & & $58.5 \%$ & $41.5 \%$ & $100.0 \%$ \\
\hline
\end{tabular}

\section{TABLE 4: Association between missed and canceled appointments}




\section{Cureus}

\begin{tabular}{|c|c|c|c|}
\hline Should Another Appointment Automatically Be Sent? & $\begin{array}{l}\text { Patients Who Missed an } \\
\text { Appointment }\end{array}$ & $\begin{array}{l}\text { Patients Who Never Missed an } \\
\text { Appointment }\end{array}$ & Total \\
\hline Yes 106 & 79 & 57 & 136 \\
\hline No 30 & 56 & 80 & 136 \\
\hline Do not know 0 & 0 & 0 & \\
\hline Total 136 & 136 & 136 & \\
\hline When Should an Appointment Be Sent? & Frequency & $\%$ & \\
\hline No answer provided & 33 & 24 & \\
\hline After the first missed appointment & 69 & 50.3 & \\
\hline After every missed appointment & 35 & 25.5 & \\
\hline Total & 137 & 99.5 & \\
\hline \multirow{2}{*}{$\begin{array}{l}\text { If you fail to attend an appointment without prior notification } \\
\text { does it matter to you? }\end{array}$} & Yes & No & $\begin{array}{l}\text { Don't } \\
\text { know }\end{array}$ \\
\hline & 81 & 29 & 26 \\
\hline \multirow{2}{*}{ Do you think missing an appointment affects the clinic? } & Yes & No & $\begin{array}{l}\text { Don't } \\
\text { know }\end{array}$ \\
\hline & 99 & 12 & 24 \\
\hline
\end{tabular}

TABLE 5: Response to the consequences of missed appointments among the surveyed sample

Seventy-nine patients who had previously missed a dental appointment believed that another appointment should automatically be given to a patient once he/she misses an appointment, while 80 patients who never missed an appointment answered in the negative. When asked if missing an appointment affects the clinic, 99 patients who had previously missed an appointment answered in the affirmative, while only 12 respondents who had never missed dental appointments said it did not affect the clinic.

\section{Discussion}

No-shows for scheduled appointments are a frequent occurrence, creating unused appointment slots, reducing patient quality of care and access to services, while increasing loss to follow-up and medical costs [1]. The study purpose was identifying factors that lead to patients missing their dental appointments in Eastern Province Military Hospitals, Dhahran. In our research, the percentage of missed appointments was found to be $58.1 \%$, which is higher than the $24.8 \%$ reported in a study conducted in Riyadh, Saudi Arabia [9] and the $36.8 \%$ reported in a study in India [4]. Our study calculated $54.4 \%$ of the participants who canceled dental appointments in the past, which is higher than the $40.5 \%$ in Dr. Salwa Alsadhan's study [9]. Out of our study population, $36 \%$ of patients preferred morning appointments, while $56 \%$ preferred afternoon appointments, which means that if these patients (56\%) were given a morning appointment, they would most likely miss it, as their preference was an afternoon appointment.

The most common reasons for missing an appointment were forgetting about it (24.3\%) and the inability to get time off either from work or school (15.4\%), which is consistent with the findings of most of the previous studies [9-13]. In our research, we found that only $1.5 \%$ of patients feared dental treatment, while the unavailability of transport accounted for $0.7 \%$ of missed appointments. Dr. Salwa Alsadhan's study identified $9.1 \%$ of patients claiming lack of transport as the reason for missing their dental appointment [9]. For canceling an appointment, inability to get time off from work/school was the most common reason (22.1\%), which is similar to a number of studies [9,14] but different from a study done in 1991, which stated illness to be the most common reason [15]. Dislike of treatment for the cancelation of an appointment was the least common (0.7\%) in our study while being most prevalent in a study conducted in the United Arab Emirates [16]. The association between canceling and missing an appointment (Table 4) was found to be statistically significant $(\mathrm{p}=0.00$ ), which might indicate that patients who canceled their appointments were more likely to miss an appointment (73\%) compared to patients who never canceled their appointments (41\%). In our research, $60.3 \%$ of participants still relied on their personal diary to remember appointments (Table 2), which could be a reason for the high rate of missed appointments, as $24.3 \%$ stated they forgot their appointment (Table 3). Studies suggested a high percentage of individuals making a mental 
note of their dental appointments [9]. It would be reasonable to assume that missed appointment rates could be reduced if patients were advised to use their mobile phones/computers to record and remember their appointments and if reminder messages/confirmation calls were sent to patients a day prior to their appointment $[2,4,9,11]$. However, some studies point out that the effect of reminder calls is not confirmatory [12], thus underlining the importance of further, large sample studies.

In our study, females were found to cancel and miss dental appointments more than males although the differences were insignificant ( $p=0.64$ and $p=0.21$, respectively). These numbers differ from a study [17] that suggested males having a higher missed appointment frequency while others suggested females miss more appointments [14].

Fifty-nine percent of respondents felt that missing an appointment was important to them, while $72 \%$ stated that it could affect the work of the clinic but still believed that automatic appointments should be given to patients who missed their appointments and a charge be made for such missed appointments (Table 5), which has been suggested by some researchers [18-19].

In dental practice, missing appointments can disrupt the patients' treatment to a large extent. For example, orthodontic treatment relies on regularly adjusting appliances and monitoring the progress of occlusal changes, whereas the early detection and treatment of carious lesions and gingival and periodontal disease demand regular dental visits, and missing appointments can seriously limit treatment efficiency. Therefore, to control missed and canceled appointments, the dental team must educate the patient on their first visit and cautiously communicate the importance of maintaining the appointment schedule and its effect on treatment outcomes. The patient should also be told how and when they can inform the clinic in case they were unable to make it to their appointment [20].

Future studies should focus on the methods that can reduce or eliminate missed and canceled appointments and encourage patients' attendance in order to enhance the treatment outcome in addition to improving the economics and quality of dental practice.

\section{Conclusions}

Our study identified a high percentage of patients who miss their dental appointments in the Eastern Province Military Hospitals, Kingdom of Saudi Arabia, causing not only detrimental effects for the patient community but also a wastage of resources at military hospitals. Since the major reasons found were a lack of reminder message and appointments scheduled at inconvenient timings, steps to reduce the frequency of missed appointments should include sending reminder messages to patients, giving preference to their schedules for appointments, giving them shorter appointments, reducing the intervals between subsequent appointments, and educating them regarding the treatment plan to reduce anxiety. Our study sample was small and centered around military hospitals, which may not be representative of the entire population. New studies should be conducted with a larger representative sample size to investigate factors responsible for no-shows so that steps can be taken to prevent them.

\section{Appendices}

Appendix A

\section{O N F I D E N T I A L}

Dear Patients:

Please take a few minutes to answer this questionnaire about the following study titled

“Why Patients Miss Dental Appointments in the Eastern Province Military Hospitals, Kingdom of Saudi Arabia.”

"Participation is optional and opting not to participate in this survey shall not in any way affect your professional status or relationship with the students. The intent of this survey is harmless and the information provided will remain strictly confidential and will never be used for purposes other than the intended purpose of this study.

Thank you for your cooperation.

Principal Investigators:

Dr. Ambreen Shabbir

Lt. Col./Dr. Mohammad Al Zahrani 


\section{Cureus}

Prince Sultan Military College of Health Sciences,

Department of Dental and Oral Health,

Dhahran, 31932

Cell phone 966556966683

Phone 966-3-8440000, Ex. 6756

Fax\# 966-3-840-5577

Questionnaire:

We would be grateful if you would take a few minutes and complete this questionnaire.

Please tick the appropriate box.

1. Age:

2. Gender: Male Female

3. Occupation: Student Employee Other (specify)

4. Education: Illiterate Elementary Intermediate

Secondary University and above

5. How do you remember your appointment date?

Diary

Mobile

Calendar

Memory

Another person

Other (specify)

6. Have you ever had to cancel an appointment at this clinic? Yes No

If the answer is no to Q6, please skip Q7.

7. Reasons for canceling an appointment (you can choose more than one answer)

Inconvenient timing

Unable to get off work/school

Unable to get transport

Sickness

Fear of treatment

Dislike of treatment

Other reasons (please specify)

8. Have you ever failed to attend an appointment at this clinic without prior notification? No 


\section{Cureus}

If the answer is no to Q8 then please skip Q9.

9. Reasons for failing to attend an appointment (you can choose more than one answer)

Forgetfulness

Unable to get time from work/school

Unable to get transport

Sickness

Fear of treatment

Dislike toward treatment

Other reasons (specify)

10. If a patient fails to attend an appointment, do you think that another appointment should

automatically be sent to them? Yes No

11. If yes, when do you recommend should an appointment be sent?

After the first missed appointment

After every missed appointment

12. If you fail to attend an appointment without prior notification:

Does it matter to you? $\quad$ Yes No Don't know

Do you think it affects the clinic? Yes No Don't know

13. If you need to change an appointment, how much notice do you think should be acceptable to the hospital/clinic?

At least 24 hours before appointment time

Less than a week

One week

More than a week

14. What is your preferred time for attending an appointment?

Early morning

Late morning

Early afternoon

Late afternoon

No preference

15. How do you think a patient who misses his/her appointment should be dealt with?

Do not give him/her new appointment before 6 months.

Put him/her on the waiting list.

They should not be given any further appointments at all. 
Thank you for your cooperation in completing this questionnaire.

\section{Additional Information \\ Disclosures}

Human subjects: Consent was obtained by all participants in this study. Institutional Review Board (IRB), Prince Sultan Military College of Health Sciences, Dhahran, KSA. issued approval RU-2016-SGP-009. We are pleased to inform you that student graduation project with details mentioned below was reviewed with no further comments. Title: Why patients miss dental appointments? Application \#: RU-2016-SGP-009 Funding source: Non-funded Principal investigator: Col. Mohammad Alzahrani and Dr. Ambreen Shabbir . Animal subjects: All authors have confirmed that this study did not involve animal subjects or tissue. Conflicts of interest: In compliance with the ICMJE uniform disclosure form, all authors declare the following: Payment/services info: All authors have declared that no financial support was received from any organization for the submitted work. Financial relationships: All authors have declared that they have no financial relationships at present or within the previous three years with any organizations that might have an interest in the submitted work. Other relationships: All authors have declared that there are no other relationships or activities that could appear to have influenced the submitted work.

\section{Acknowledgements}

We would like to thank Armed Forces Hospital in Jubail, King Fahd Military Medical Complex in Dhahran, and Airbase Hospital in Dhahran for allowing us to conduct research in their dental departments. We would also like to extend our appreciation to Mr. Zachariah Arulananathacn for the analysis of study data.

\section{References}

1. Davies ML, Goffman RM, May JH, Monte RJ, Rodriguez KL, Tjader YC, Vargas DL: Large-scale no-show patterns and distributions for clinic operational research. Healthcare. 2016, 4:1-15. 10.3390/healthcare4010015

2. Almog DM, Devries JA, Borrelli JA, Kopycka-Kedzierawski DT: The reduction of broken appointment rates through an automated appointment confirmation system. J Dent Educ. 2003, 67:1016-1022.

3. Worsley DJ, Marshman Z, Robinson PG, Jones K: Evaluation of the telephone and clinical NHS urgent dental service in Sheffield. Community Dent Health. 2016, 33:9-14. 10.1922/CDH 3676Worsley06

4. Tandon S, Duhan R, Sharma M, Vasudeva S: Missed dental appointments between the cup and the lip: missed dental appointments. J Clin Diagn Res. 2016, 10:122-124. 10.7860/JCDR/2016/17400.7842

5. Lapidos A, Shaefer HL, Gwozdek A: Toward a better understanding of dental appointment-keeping behavior. Community Dent Oral Epidemiol. 2016, 44:85-91. 10.1111/cdoe.12193

6. Albaloushi HM, Da'ar O: Do patients with varying demographic and regional characteristics equally miss appointments across dental specialties?. Eur Sci J. 2015, 11:45-60.

7. Murdock A, Rodgers C, Lindsay H, Tham TCK: Why do patients not keep their appointments? Prospective study in a gastroenterology outpatient clinic. J R Soc Med. 2002, 95:284-286. 10.1177/014107680209500605

8. Standards for the dental team. General Dental Council. 2013, Accessed: February 9, 2018 : https://standards.gdc-uk.org/pages/principle2/casestudies/casestudy1.aspx.

9. Alsadhan SA: Frequency of missed and cancelled appointments in King Saud University orthodontic clinic . Saudi J Dent Res. 2013, 4:77-80. 10.1016/j.ksujds.2013.04.001

10. Skaret E, Raadal M, Kvale G, Berg E: Factors related to missed and cancelled dental appointments among adolescents in Norway. Eur J Oral Sci. 2000, 108:175-183. 10.1034/j.1600-0722.2000.108003175.x

11. Can S, Macfarlane T, O’Brien KD: The use of postal reminders to reduce non-attendance at an orthodontic clinic: a randomised controlled trial. BDJ. 2003, 195:199-201. 10.1038/sj.bdj.4810443

12. Bos A, Hoogstraten J, Prahl-Andersen B: Failed appointments in an orthodontic clinic . Am J Orthod Dentofacial Orthop. 2005, 127:355-357. 10.1016/j.ajodo.2004.11.014

13. Storrs MJ, Ramov HM, Lalloo R: An investigation into patient non-attendance and use of a short-message reminder system at a university dental clinic. J Dent Educ. 2016, 80:30-39.

14. George AC, Hoshing A, Joshi NV: A study of the reasons for irregular dental attendance in a private dental college in a rural setup. Indian J Dent Res. 2007, 18:78-81. 10.4103/0970-9290.32425

15. Trenouth MJ, Hough A: Reasons for broken and canceled appointments in a British orthodontic clinic . J Clin Orthod. 1991, 25:115-120.

16. Ismail AI, Saeed MH, Al-Silwadi FM: Missed dental appointments in the United Arab Emirates. J Int Dent Med Res. 2011, 4:132-138.

17. Skaret E, Raadal M, Kvale G, Berg E: Missed and cancelled appointments among 12-18-year-olds in the Norwegian Public Dental Service. Eur J Oral Sci. 1998, 1:1006-12. 10.1046/j.0909-8836.1998.eos106605.x

18. Dubé-Baril C: Charging for missed appointments. J Can Dent Assoc. 2009, 75:33-34.

19. Levin RP: How to manage the behavior of patients who disregard scheduled appointment times . J Am Dent Assoc. 2018, 29:172-173. 10.14219/jada.archive.2012.0129

20. Christensen AA, Lugo RA, Yamashiro DK: The effect of confirmation calls on appointment-keeping behavior of patients in a children's hospital dental clinic. Pediatr Dent. 2001, 23:495-498. 